\title{
"Will steroids kill me if I use them once?" A qualitative analysis of inquiries submitted to the Danish anti-doping authorities
}

\author{
Ask Vest Christiansen ${ }^{\mathrm{a}, *}$, Jens Bojsen-Møller ${ }^{\mathrm{b}}$ \\ a Department of Public Health, Section for Sport Science, Aarhus University, Dalgas Avenue 4, DK-8000 Aarhus C., Denmark \\ ${ }^{\mathrm{b}}$ Norwegian School of Sport Sciences, Department of Physical Performance, Sognsveien 220, N-0806 Oslo, Norway
}

\section{A R T I C L E I N F O}

\section{Article history:}

Received 2 December 2011

Received in revised form 17 April 2012

Accepted 8 May 2012

\section{Keywords:}

Anabolic androgenic steroids

Anti-doping education

Recreational athletes

Doping controls

Harm reduction

Denmark

\begin{abstract}
A B S T R A C T
Background: The Danish strategy for fighting the use of anabolic androgenic steroids in fitness centres is likely the most comprehensive of its sort in the world. It is instituted in the national anti doping organisation, Anti Doping Denmark (ADD), and consists of doping controls, educational campaigns, and anonymous counselling through a web-based email service.

Aim and method: Inquiries that were submitted to ADD's web-based counselling service over an 18-month period were explored with the aim to identify and analyse differences in concerns and approach to the counselling service. Two categories of inquiries were the focus of attention: (1) those addressing side effects of anabolic steroids and (2) those addressing concerns for receiving a positive doping test after the use of supplements.

Results and discussion: In the first category four different types of approaches were identified and inquirers' concerns analysed: (a) those that lacked knowledge on anabolic steroids, (b) those that had experienced side effects, (c) those that expressed knowledge of anabolic steroids, and (d) those that presented potential harm reduction dilemmas for the service. The second category revealed noteworthy concerns as a result of the legislation on the issue.

Conclusion: The approach to the counselling service and the knowledge of health consequences of the drugs consumed differed substantially between the two categories and groups of inquiries.

Implications: In order to educate the target group about anabolic steroids there is a need for the involved organisations to consider harm reduction policies in adjunct with the often applied zero tolerance approach.
\end{abstract}

(c) 2012 Elsevier Ltd. All rights reserved.

\section{Background}

During the last decade increased academic and media attention has been allotted to the use of performance enhancing substances outside elite sports. Especially the use of anabolic androgenic steroids (hereafter: anabolic steroids) associated with training in fitness centres have been studied and debated (e.g. Barland \& Tangen, 2009; Bilard, Ninot, \& Hauw, 2011; Christiansen, 2009; Eklöf, Thurelius, Garle, Rane, \& Sjöqvist, 2003; Evans-Brown \& McVeigh, 2009; Grogan, Shepherd, Evans, Wright, \& Hunter, 2006; Kanayama \& Pope, 2012; Klein, 1993; Mangweth et al., 2001; Monaghan, 2001, 2002; Parkinson \& Evans, 2006; Pope, Phillips, \& Olivardia, 2000; Probert, Palmer, \& Leberman, 2007; Skårberg, Nyberg, \& Engstrom, 2008; Striegel et al., 2006; Thompson \& Cafri, 2007). Unlike the situation in elite sports there is no international coordinated effort to fight the use of drugs in fitness and strength

\footnotetext{
* Corresponding author. Tel.: +45 87168182.

E-mail address: avc@sport.au.dk (A.V. Christiansen).
}

training environments (Anti Doping Danmark, 2012c). However, in line with a few other countries the national anti-doping organisation in Denmark, Anti Doping Denmark (ADD), has by law had the obligation to not only fight the use of performance enhancing substances within elite sports, but since 2005 also to address the use of drugs in fitness centres and gyms (hereafter: gyms) (Retsinformation, 2004). The Danish strategy for fighting drug use in gyms is very likely the most comprehensive of its sort in the world, and is unique in that ADD control officers can perform doping controls on any individual exercising in a gym that is part of the national anti-doping scheme. Under the scheme, which in 2010 embraced approximately $80 \%$ of all Danish gym-members, doping controls are conducted in agreement with the World Anti Doping Code (WADC) (Steele et al., 2010; Anti Doping Danmark, 2012c). Thus, gym members are tested and sanctioned according to the same standards as elite athletes. The strategy for fighting drug use in gyms is thus largely in line with that in elite sport, in that it consists partly of doping controls, partly of educational campaigns and an elaborated website (Anti Doping Danmark, 2012b). Besides being a comprehensive source of information, the website also 
Table 1

Affiliation of the enquirers. Absolute and relative number of queries and the distribution on gender within each affiliation-category.

\begin{tabular}{lcccccc}
\hline \multirow{2}{*}{ Affiliation } & \multicolumn{2}{l}{ Number of queries } & & \multicolumn{3}{c}{ Gender distribution } \\
\cline { 2 - 3 } \cline { 6 - 7 } \cline { 5 - 7 } & Absolute & Relative (\%) & & Male & Female & Unknown \\
\hline Gym & 763 & 55 & & 672 & 46 & 45 \\
Sports & 174 & 12 & & 116 & 24 & 34 \\
Relative/peer & 160 & 11 & & 63 & 78 & 19 \\
Health personnel & 9 & 1 & & & & \\
Other & 11 & 1 & & 7 & 2 & 2 \\
Unknown & 281 & 20 & & 103 & 28 & 150 \\
Total & 1398 & $100 \%$ & & 967 & 180 & 251 \\
\hline
\end{tabular}

Adopted from Bojsen-Møller and Christiansen (2010).

offers anonymous counselling. Individuals in search for information on performance enhancing drugs and other related substances can either make a telephone call to the hotline service or submit questions via the website, and ADD's consultants will then provide inquirers with an answer. Anti doping hotline services also operate in Sweden, Norway, Holland and France (Bilard et al., 2011; Eklöf et al., 2003; Sjöqvist, Garle, \& Rane, 2008).

Contact with ADD's consultancy service is voluntary and open for everyone. Therefore especially inquiries to the web-based service are often characterised by spontaneity and openness on the inquirer's part. With its spontaneous and easy access structure the database thus constitutes a content rich and fruitful research observatory for insight into inquirers' interests, motives, experiences, behaviours and concerns related to doping. However, the open structure also entails that the only information available is that which the inquirer chose to submit.

In this article inquiries that were submitted to ADD's web-based counselling services over the 18-month period from 1 January 2006 to 30 June 2007 are analysed with a qualitative approach. The data material has previously been quantitatively examined and categorised (Bojsen-Møller \& Christiansen, 2010). Although the web-based system automatically required submission of questions in one of seven categories, a large number of inquiries were posted in wrong categories. Combined with the fact that the individual inquiry only contained the information the inquirer chose to provide, the researchers re-categorised all inquiries into an information matrix resembling that of Eklöf's group in their study of Swedish anti-doping hotline inquiries (2003). Thus, a total of 1398 inquiries were categorised with respect to question type, age and gender of the inquirer, the affiliation of the inquirer (e.g. competitive sport or the gym-sector), whether he or she used or considered using substances, what type of substance(s) and whether the inquirer expressed concerns regarding personal health or regarding the legal status of a specific drug or substance (Bojsen-Møller \& Christiansen, 2010).

The typical user of ADD's counselling service was a male between 15 and 25 years who exercised in a gym. A majority of inquiries came from individuals doing non-competitive gym exercise. Approximately $10 \%$ were posted by individuals participating in sports, and only a fraction of these (less than $0.5 \%$ ) were elite athletes. Almost all questions that were posted by individuals training in gyms were from male inquirers (94\% male, $6 \%$ female) (Table 1 ). Competing bodybuilders would typically use other Internet forums than ADD for obtaining information about anabolic steroids. Thus, subjects in this study are not experienced bodybuilders, but are to be found on a continuum from the semi-experience gym users at one end to the novice at the other.

The available age data (age was known for only $25 \%$ of all inquirers) indicate that individuals who considered use of anabolic steroids or similar drugs were younger ( 19 years, $S D=5$ ) than the average inquirer ( 25 years, $S D=11$ ), and were significantly younger
( $p<0.01$, Student's $t$-test) than those who stated present or previous use of such substances (26 years, SD $=10$ ) (Bojsen-Møller \& Christiansen, 2010). These figures are in line with what has been found for users of the Swedish anti-doping hotline (Eklöf et al., 2003; Sjöqvist et al., 2008).

The majority of questions involved reference to a certain substance or group of substances. While most questions were concerned with either anabolic steroids or creatine and protein supplements, there were also a number of questions on other dietary supplements (Table 2). Also this distribution is comparable to that of Eklöf et al. (2003).

When comparing to elite sports, where use of drugs is usually concealed (e.g. Møller, 2010; Waddington \& Smith, 2009), it is noteworthy that $15 \%$ of inquirers indicated current or previous use of anabolic steroids or similar drugs; a figure that is in line with the 17\% found by Eklöf et al. (2003). Taking into account that the recipient of the inquiry was an anti-doping organisation it was surprising that an additional $15 \%$ of inquirers indicated that they were planning or considering use of such substances (Bojsen-Møller \& Christiansen, 2010). In the Swedish study this category of inquirers amounted to only 6\% (Eklöf et al., 2003). This indicates that ADD's service is considered a trustworthy platform for information on performance enhancing drugs for individuals considering such use. Such individuals might turn to ADD because they on the one side do not rely on the knowledge dispersed from other sources within the environment, and on the other mistrust physicians' knowledge on the issue (Pope, Kanayama, Ionescu-Pioggia, \& Hudson, 2004; Grogan et al., 2006).

The quantitative analysis of the database is beneficial in that it provides an overview of who is using the anti-doping counselling system, what types of questions they are generally asking, concerning what class of drugs. Such information is useful in getting to know general concerns among users and potential users of drugs and dietary supplements. On the other hand the quantitative analysis does not provide much understanding of the interests, motives, behaviours, experiences, concerns and meaning these individuals attribute to using potentially harmful drugs.

As noted, the voluntary nature of inquiry submission to ADD's web-service means that the submitted inquiries are characterised by spontaneity and nearness to the thoughts and feelings of the inquirer. At the same time most inquiries are short, usually between 50 and 150 words, and only include the content chosen by the inquirer. The disadvantage is that it is not possible to gather additional information as in a qualitative interview; the advantage that inquirers voluntarily provide information regarding concerns, meaning and purpose which they were not invited to provide. The database of inquiries thus makes up fruitful observatory for research with a possibility to gain insight into the meaning behind drug- and supplement use. As emphasised by others (e.g. Monaghan, 2002; Skårberg et al., 2008; Grogan et al., 2006), if researchers want to understand why drug users behave as they do, it is necessary to study the social meanings they attach to medically defined risk behaviour. The authors consider the inquiries in the database to be a unique entry to such knowledge.

\section{Purpose and research questions}

The present analysis focused on inquiries from individuals training in gyms. Two categories of inquiries were examined: (1) those addressing the use of anabolic steroids and their side effects and (2) those expressing concern for obtaining a positive doping test. There are two basic premises for this focus: (a) the explicit societal concern for the use of anabolic steroids in gyms, and (b) the exceptional legislative steps taken in Denmark (including the use of doping controls in gyms) to counter this use (Anti Doping Danmark, 
Table 2

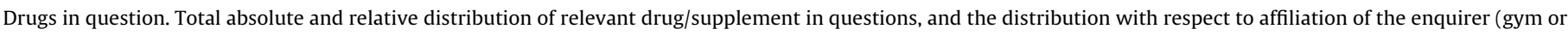
sport) and gender.

\begin{tabular}{|c|c|c|c|c|c|c|}
\hline & Number of queries & Distribution (\%) & Gym sector & Sport & Male & Female \\
\hline AAS & 374 & 34 & 227 & 4 & 284 & 40 \\
\hline Prohormones. & 53 & 5 & 41 & 1 & 48 & 3 \\
\hline $\mathrm{HGH}$ & 37 & 3 & 20 & 3 & 26 & 6 \\
\hline Insulin & 5 & 0 & 4 & - & 5 & 0 \\
\hline EPO/blood doping & 35 & 3 & 0 & 1 & 7 & 2 \\
\hline Stimulants & 10 & 1 & 8 & - & 3 & 1 \\
\hline Creatine/protein suppl. & 237 & 22 & 194 & 15 & 209 & 11 \\
\hline 'Fat-burner' suppl. & 67 & 6 & 41 & 1 & 30 & 23 \\
\hline Dietary suppl. & 171 & 16 & 104 & 17 & 120 & 14 \\
\hline Other & 100 & 9 & 18 & 30 & 42 & 9 \\
\hline Total & 1089 & $100 \%$ & & & & \\
\hline
\end{tabular}

Adopted from Bojsen-Møller and Christiansen (2010).

AAS, anabolic androgenic steroids; HGH, human growth hormone.

2012c; European Commission, 2007; Retsinformation, 2004). Further, if public institutions aim at countering illicit drug use, it is imperative to study the social meanings which drug users attach to their risk practices, in order to enhance the communication with this group.

In the present study the meaning and content of the above two categories of inquiries, are examined with respect to the following question: What are the motives, interests and concerns for individuals who submit inquiries about performance enhancing substances to ADD? And subsequently; what consequences for anti-doping education can be drawn from this? Thus, whereas the quantitative study described who used ADD's inquiry service, the present study aims to provide some understanding of how and why inquirers use the counselling service and put this into perspective of present anti-doping education. Hence, the object of study has shifted from quantification of data subtracted from all inquiries, to interpretation of content and meaning embedded in a certain category of inquiries.

\section{Design and methods}

The analysis focused on inquiries from subjects that have used, use or consider using anabolic steroids and involve an interest in or concern for a drug's potential side effects (427 out of the total 1398). Since Danish legislation requires ADD to perform doping controls on recreational athletes in gyms, the analysis also considered inquiries expressing concern for obtaining a positive doping test and the resulting ban (184 out of the total 1398). Inquiries from individuals asking general questions about training, diets, creatine, protein, herbal products and other diet supplements have thus been omitted. Inquiries from individuals participating in sport (recreational or elite) have similarly been omitted. Also telephone calls to the hotline service have been disregarded since the archived information was limited and did not allow for qualitative analysis.

The present analysis is thus exceptional in that it builds on written material from subjects voluntarily submitting inquiries to an anti-doping organisation, expressing their questions and concerns, whereas previous analysis on anti-doping consultancy programmes have relied on material collected from telephone conversations (Eklöf et al., 2003; Bilard et al., 2011).

Virtually all inquiries submitted to the ADD were in Danish so the examples presented in the following have been translated by the authors. While spelling and grammatical errors have been omitted in the translated examples, we have attempted to maintain the style and framing of the questions as close to the original as possible, in order to mediate an image of the subject behind the inquiry.
As is the case for all institutions with a public interface, some individuals express their critique or lack of respect by submitting parodic or hoax inquiries. Thus, the authors have been posed with the additional challenge of assessing each query for genuineness. While a few inquiries have been discarded on this behalf, others which had a content suggesting that they could be hoaxes (e.g. \#1 and 3 below), have been kept due to an overall assessment of the frequency of such questions, their wording, spelling, syntax, and grammar.

When there is reference to specific trade names of drugs in the inquiry, brief explanations of the drug in question are provided in footnotes the first time they appear (except for dietary substances). The clinical conditions inquirers address will not be considered.

ADD's specific replies to the inquiries are not considered in the present analysis; however the authors are familiar with the institution's overall policy and from communication with consultants on the service we are well aware of the spectrum of replies for the various kinds of inquiries.

The established information matrix from the quantitative study enabled us to extract inquiries that involved use of anabolic steroids or the consideration of such use as well as inquiries involving issues of concern for consuming a banned substance, which could potentially result in a positive doping test and a subsequent ban. After the relevant inquiries were extracted from the database (611 in total) the content of each inquiry was coded for further analysis using qualitative data analysis software (ATLAS.ti, version 6.2).

From the coding of the material of the first category of inquiries (subjects that have used, use or consider using anabolic steroids), four different ways of approaching the web-service appeared. The first three ('Lack of knowledge', Traditional hotline users', 'Ethnopharmacists') will be analysed under the heading 'Side effects', while the fourth group posses a separate challenge for antidoping education and will therefore be analysed separately under the heading 'Dilemmas for the counselling service?' Hereafter the second category of inquiries; 'Concerns for positive doping test' will be analysed.

\section{Results and discussion}

\subsection{Side effects}

\subsubsection{Lack of knowledge}

A number of inquiries came from boys or young men who consider use of anabolic steroids and who know that there is some sort of relationship between male hormones and their genitals, but are not quite sure what this entails, and therefore sometimes make extraordinary assumptions: 
(\#1) They say that if you introduce testosterone semen production stops and the testicles shrink! But since the body also grows on testosterone, you should actually stop masturbating (coz' you don't have enough testosterone in your body) if you want to grow. Or is that of no importance?

What is worrying is that some of these young men seem committed to engage in anabolic steroid usage even though their knowledge is scarce; often they only have trained for a short period of time, are still relatively immature and may not have stopped growing. The person in the example below has also learned that there might be side effects, but he nevertheless wants to be more muscular:

(\#2) Hi, I'm a 17 year old boy who stopped training because I was impatiently waiting to see muscles. Now I've started training again and have thought a lot about taking steroids or something else, but I'm also afraid that the penis will get smaller or that I'll get sore nipples. I've tried creatine and protein powder but didn't really feel it did any good and therefore I want to try steroids. But I've also heard that there are many different things within hormones that you can take. Is there one of them where the penis doesn't shrink and you don't get sore nipples and pimples? What should I do? I want to get bigger quicker.

It is general knowledge that there are health risks associated with anabolic steroid use. But some are apparently willing to take even psychological risks as long as their penis is not affected, as can be seen from this young man with unusual priorities: (\#3) " $\mathrm{Hi}$, I'm 15 years and want to take Thai. ${ }^{1}$ Are there any side effects to the cock? I don't care if I get sick in the head I just want to know if anything happens with the cock." What is evident from these examples is that although muscles might be considered to be the most powerful visible signifier of maleness and masculinity, developing bigger muscles is still not of such importance that the young men in question are willing to sacrifice their penis - or indeed their manhood - to become manlier. Whereas some express limited knowledge regarding the substances they consider taking, others want to convey the message that they have spent time acquainting themselves with the drugs they consider using. Usually this means that they are more specific in their questioning, although the topic of anabolic steroids' potential effect on one's manhood is still paramount:

(\#4) Hi, I consider going on a steroid cycle. I've been on a small one before with Dianabol (Thai pills). I will continue this but also combine with Test $\mathrm{E}^{2}$ and $\mathrm{EQ}$ (Ganabol). ${ }^{3}$ I can live with the few side effects, and I have read a lot about the different issues. So I'm not that concerned as regards my health and in addition I don't take large doses. But how big is the risk of becoming sterile? Do you have any documentation on that?

The fact that Ganabol is a trade name for the anabolic steroid boldenone, which is developed for veterinary use, mostly for treatment of horses, is illustrative of the kind of risks some individuals

\footnotetext{
${ }^{1}$ When 'Thai' is mentioned it is usually with reference to a 2,5 or $10 \mathrm{mg}$ tabletversion of the anabolic steroid Methandienone, commonly known as Dianabol and often imported from Thailand. Dianabol was developed by John Ziegler after he attended the world championships in weight-lifting in 1954 as a team doctor, and saw how the testosterone using Soviet athletes outperformed the American athletes. Sources: http://en.wikipedia.org/wiki/Methandienone [visited 10 May 2011] and (Todd, 1987).

2 Test $\mathrm{E}$ is short for testosterone enanthate which is an oil-based injectable steroid. It has been used for treatment of male hypogonadism and investigated as a potentially highly effective male contraceptive.

3 Equipoise (EQ), Ganabol, Equigan and Ultragan are all trade names for the anabolic steroid boldenone. Boldenone is an anabolic steroid developed for veterinary use, mostly for treatment of horses. In the US it is not indicated for use in humans and is only available through veterinary clinics. Source: http://en.wikipedia.org/wiki/Boldenone [visited 18 April 2011].
}

are willing to take, even if they consider themselves to be well informed on the issue.

\subsubsection{Traditional hotline users}

Unsurprisingly there are a number of individuals who use the web-service to inquire about side effects they have experienced in connection with the use of anabolic steroids. Most of these individuals now know that they were naïve when they began using anabolic steroids. Some simply describe their symptoms and ask for guidance: (\#5) "Six months ago I was stupid enough to use testosterone for 6 weeks. Suddenly I get sore nipples. This has now developed into small hard balls that grows and grows! What do I do? Should I contact a doctor?" Gynecomastia (the formation of male breast tissue) is a well-known side effect related to anabolic steroid use, which in strength training milieus often is referred to as 'bitch tits'. Another inquirer has experienced a stinging sensation in his arms which now causes anxiety:

(\#6) I have a question that I want an answer to as quickly as possible, because it worries me a lot. I am currently on a well thought-out cycle consisting of Test E [testosterone enanthate], stacked with Dianabol, which I started almost 2 weeks ago. For the last few days I've had a strange feeling in my arms and hands. The arms feel a bit like the growing pains we can have in the legs, but it isn't just the joints but rather the WHOLE arm. The hands feel a bit like a bloated balloon. My conclusion would be that it was fluid accumulation, given that this is normal. But I'm not sure and therefore hope for a solid answer I can really use.

Yet others have not only experienced physical but also psychological side effects:

(\#7) I am soon a man of 20 years. For a month ago I stopped my first and final cycle. I've been (un)lucky enough and had "only" one adverse reaction: I've got a depression, and my question is how long it takes before my hormone production is back to normal? To all of you who consider steroids: Keep your hands off it. It's not worth it.

Examples 5-7 are typical for individuals who have experimented with anabolic steroids and subsequently suffered clinically well described adverse effects and now seek professional advice on how to deal with their symptoms and perhaps get some relief for their anxieties. Some even address other users of the webservice directly, informing them about the potential risks involved in steroid use:

(\#8) Beware! You play with YOUR LIFE! I know it's not what you want to hear, but after only 8-9 cycles, it [steroids] has done me permanent harm! I can't sleep on my left side due to pain from the area around the heart, there's a stinging sensation in my arm and it goes to sleep. I still have problems with my potency 2 years after and I've experienced that I'm in a bad mood almost every day. And then of course there are all the other things such as hair loss, etc. Good luck!

Such examples of real people with real concerns and sufferings are part of the core rationale for having a public funded web consultancy service where users of anabolic steroids can be advised on how to deal with their symptoms and one can seek to convince potential users not to use anabolic steroids. However, although there are quite a few inquiries pertaining to the specific experience of adverse effects, they do not dominate the group of inquiries on anabolic steroids.

\subsubsection{Ethnopharmacists}

Fifteen percent of all inquirers inform ADD that they seriously consider using anabolic steroids (Bojsen-Møller \& Christiansen, 2010), and many of these want to know what kind of anabolic 
steroids are the most safe. They might not rely on the person who sold them the drugs and therefore make contact with ADD whom they may regard more knowledgeable in these matters. Many add that they know there are risks associated with steroid use, but that these risks are likely to be minimal in their case, since they will only take one cycle (or course). Some compose long, detailed questions while others keep it short and simple: (\#9) "Hi ADD, What happens if you try steroids just once? Will you become bigger and is it dangerous to try them for just one time?" The fact that inquirers often emphasise that they will take one cycle only, indicates that they have learned that repeated use can be health damaging. However, like many others in the subculture they seem to believe that steroids used in moderation is safe (Grogan et al., 2006; Monaghan, 2002). In spite of the potential risk they therefore still want the effect of drug:

(\#10) After long time's consideration I have decided for a cycle that'll blow me up a bit in my strength training. The idea is to inject the male hormone TESTOSTERONE into the body. This will be done over 10 weeks with 2 injections per week, i.e. 20 injections in total. And I REPEAT, this is the first and LAST time I'll try it, there'll be no multiple cycles. I wanna hear if I'll die from this one time? I know my question sounds totally weird, but I am a person, who cares about his wellbeing, and therefore eat very healthy and exercise a lot. I'd also like to hear if anything such as cardiac arrest or similar would happen to me after I've injected the male hormone? And what are the side effects? I really hope you'll answer me, as this will make me much wiser! But I repeat; I will not go on a cycle ever again!

It is easy to point to the lack of coherence in a person's attitudes when he stresses that he lives a healthy life and cares about his wellbeing, while simultaneously planning to inject testosterone. However, while he knows this ("I know my question sounds totally weird"), he is not alone in framing his question this way. When inquirers emphasise that they will only take one course, some probably do so because it is their genuine intention. It may however, also serve the aim of signalling that they are in control of the situation and not someone that will end up as a drug addict (Kanayama \& Pope, 2012; Skårberg et al., 2008). It can thus be seen as a strategy intended to increase the chances of getting a more fact-based answer related to the documented side effects of the drug in question. They know that ADD's objective is to fight the use of doping, and they might reckon that if they appear to be unreflective (as some of the above inquirers), chances are that they will receive an answer that does not relate to the content of their question, but instead one that in standardised phrases will seek to persuade them not to use drugs at all.

In spite of the difference in approach and style, inquirers most often appear to have a genuine interest in getting to know the side effects, which, they claim, can make their risk-assessment more informed. Following Welsh sociologist Lee Monaghan, the knowledge these inquirers can be said to posses, can be categorised as 'ethnopharmacological knowledge', which is lay people's "detailed subcultural understanding of the pharmacological properties of particular compounds, consisting of a taxonomy of different steroids, dosages, administration routes and complex cycling theory" (Monaghan, 2001). The interest in having such knowledge confirmed by an authority like ADD is visible in the following example:

(\#11) Hi ADD, I'm a (relatively) sensible guy who've trained a number of years! I feel I've come to a standstill, and would like to gain the last kilos through chemistry to achieve my goal with my body. I write that I'm sensible because I've tried to read as much as possible, and really just want to hear whether some of the facts I've been looking at may be true. I've for example considered a cycle consisting of Primobolan Depot ${ }^{4}$ and Turanabol, ${ }^{5}$ a variation of D-bol [Dianabol], which reportedly shouldn't cause gyno [gynecomastia]. I've chosen Primo D [Primobolan Depot] because it has minimal side effects, leave little edema, doesn't aromatize to estrogen, doesn't affect the liver, and your serum cholesterol levels will not be changed either. Also the body's own production of test [testosterone] is only affected by really high doses! My plan is to run a Post Cycle Therapy with Nolvadex. ${ }^{6}$ Well, I just want to hear if this plan is crazier than most other horror scenarios you hear about? And whether some of my facts are right? I mean you've heard about well functioning people who have been on juice [anabolic steroids] for years! Although that isn't my intention at all!

Again, it appears that a main theme for the inquirer is to convince the ADD consultant that this is not a case of potential prolonged substance abuse, but instead the inquirer wants to convey the message that he has paid careful attention to the facts he could find and now wants a second opinion on what he has learned. It is not his "intention" to be on drugs "for years". While he has done some efforts to gain knowledge of the various drugs, he probably - and in line with many other inquirers - is not aware that studies documenting the health consequences on humans of the drugs and doses they inquire about, including the use of multiple drugs at the same time (so-called 'stacking regimes'), do not exist due to research-ethical reasons (e.g. Hartgens \& Kuipers, 2004; Kanayama \& Pope, 2012).

As it further appears from the above quotes, some users of the web-service have the impression that ADD provides all sorts of guidance. It is, however, a fixed policy that ADD consultants do not offer counselling on which anabolic steroids are safest (or least harmful) to use and/or how to use them. This guiding principle is based on the certitude that no solid scientific platform for such guidance exists and that in recommending one regime over the other, the institution would be sending the signal that it condones a potential harmful practice. Thus, no matter how determined the individual may seem, ADD's consultants apply a zero tolerance policy and thus always advice not to use anabolic steroids. In most cases it is uncomplicated to employ this policy. There are instances, however, where it may be easier said than done to balance this policy against the aspiration to provide guidance that in the best possible way can safeguard inquirers' health. More mature inquirers who have trained for several years, for instance, tend to have a more sophisticated approach to the subject:

(\#12) Hey, I'm a 25 year old bloke who've trained for 7 years and had okay results. I just don't grow anymore. I've thought about going on a small Primobolan cycle $(200 \mathrm{mg} /$ week for 8

\footnotetext{
${ }^{4}$ Primobolan (tablet form) or Primobolan Depot (injectable) is the common brand names for the anabolic steroid methenolone enanthate, or metenolone enanthate, which is an ester derivative of methenolone. Source: http://en.wikipedia.org/wiki/Metenolone_enanthate [visited: 19 April 2011].

5 Turinabol or Oral Turinabol is the brand name for 4Chlorodehydromethyltestosterone. It is an anabolic steroid which is a chlor-substituted version of methandrostenolone (Dianabol). Turinabol was the first original product of Jenapharm, a pharmaceutical company from East Germany providing the successful East German athletes with anabolic steroids. Source: http://en.wikipedia.org/wiki/4-Chlorodehydromethyltestosterone [visited: 29 April 2011] and Spitzer (1998).

${ }^{6}$ Nolvadex is the brand name for Tamoxifen which is used to prevent estrogen related gynecomastia, resulting from elevated estrogenic levels in conjunction with steroid use. It is taken as a preventative measure in small doses, or used at the onset of any symptoms e.g. nipple soreness/sensitivity. Other drugs such as clomiphene citrate and the anti-aromatase drugs are taken for similar purposes. They are used to try to avoid the hormone related adverse effects of steroid use. Source: http://en.wikipedia.org/wiki/Tamoxifen [visited: 29 April 2011].
} 
weeks combined with $\mathrm{Clomid}^{7}$ if my own testosterone production should be suppressed). Is this in your eyes a very dangerous cycle and can I perhaps do something better? I've read a lot about primo [Primobolan] and everywhere you hear that the side effects are minimal. What can be expected from a steroid that is as mild as primo?

Compared to practice in bodybuilding milieus the suggested dose is not high. Doses at or above $2000 \mathrm{mg}$ of anabolic steroids per week are not rare among competitive bodybuilders (Kanayama \& Pope, 2012; Monaghan, 2001; Parkinson \& Evans, 2006; Perry, Lund, Deninger, Kutscher, \& Schneider, 2005). However, such extreme doses almost certainly cause various adverse effects. In Parkinson and Evans' study (2006) of 500 anabolic steroid users 60\% of respondents reported using doses above $1000 \mathrm{mg}$ per week, and $13 \%$ reported doses above $2000 \mathrm{mg} /$ week. Of the 500 respondents, $99 \%$ reported symptoms of side effects and $70 \%$ reported three or more side effects which they themselves judged to be caused by their use of anabolic steroids. In Bhasin's groundbreaking 1996-study subjects were given doses of $600 \mathrm{mg}$ testosterone enanthate per week and no serious side effects were observed (Bhasin et al., 1996). But that dosage is nonetheless well above the normal production of testosterone in a healthy male which, although oscillating and subject to change from various parameters, is around $8 \mathrm{mg} /$ day (Mottram, 2011). Although approximately 4 times higher than normal production, the risk scenario of the regime suggested by inquirer \#12 is thus different than what is reported in a number of cases and in the underground literature and on websites where detailed descriptions for various cycles can be found (Kanayama \& Pope, 2012). Nevertheless, it would still be mandatory for the consultant to reply with the advice never to take any drugs. Besides emphasising the risky business of selfadministering anabolic steroids and the possible side effects, the consultant could stress that the drug in question could be adulterated (Graham et al., 2009), and thus encourage the inquirer to keep up his work in the gym without drugs.

It is difficult to draw strict boundaries between inquirers' approach. However, as demonstrated, individuals who inquire about anabolic steroids and their side effects can generally be said to fall into three groups depending on their different ways of approaching the web-service: the first group consists of primarily younger men who are impatient and rather unreflective of their praxis and whose inquiries about anabolic steroids suggest that these individuals have an experimenting lifestyle (\#1, 2, 3, 4). Secondly, there is a group of what could be regarded traditional hotline-users; individuals who have experienced side effects from anabolic steroids and inquire for advice on how to deal with the symptoms. Part of this group uses the service as a platform to warn others (\#5, 6, 7 and 8). Finally, there is a group of individuals who use or consider using anabolic steroids as a mean to enhance their training and get further results with their 'body project'. Individuals in this group claim to be able to handle the risks and likely side effects of the drugs in a calculative manner, which seems to be part of a lifestyle where training and diet also play a dominating role (\#10, 11 and 12). Together with others, some of these individuals, however, forms a fourth group since their approach to the web-service may lead to dilemmas for the consultants.

\footnotetext{
7 Clomid is a trade name for clomifene citrate which is a selective estrogen receptor modulator (SERM) that increases production of gonadotropins by inhibiting negative feedback on the hypothalamus. It is commonly used by male anabolic steroid users to bind the estrogen receptors in their bodies, thereby blocking the effects of estrogen, such as gynecomastia (male breast formation). It also restores the body's natural production of testosterone. It is commonly used as a recovery drugänd taken toward the end of a steroid cycle. Source: http://en.wikipedia.org/wiki/Clomifene [visited 9 May 2011].
}

\subsection{Dilemmas for the counselling service?}

Since it was permanently instituted in 2005 ADD has had as its "vision [...] to fight the use of doping in Danish sport" (Anti Doping Danmark, 2012a). Behind this vision are two main arguments: one is to "strengthen the fundamental values of sport", i.e. the principle of fair play, and the other is to "secure the health of the athletes" (Evald, 2009; Retsinformation, 2004). Whereas the principle of fair play does not apply to recreational athletes of whom only very few take part in competitions (and none in this study did so), the health argument certainly does apply (Retsinformation, 2008). This is known - implicitly or explicitly - by some inquirers who seem more or less determined to use anabolic steroids, while at the same time believing that risk can be controlled and therefore inquire for advice on how to use anabolic steroids in the safest possible way:

(\#13) I want to ask a question which I believe many users of the [ADD web-] service want an answer to. Now, if one wants to try a steroid cycle with Deca $^{8}$ etc., and you know the side effects, what can you then do to get a good result and also reduce the side effects? How should you train, what should you eat etc. I think it would be a good idea to mention it because many get scared when reading what you're writing, but there are just as many who do it [take steroids] anyway. So in order to help them do it in a way so it won't go wrong. Can you give such an advice?

Another inquirer bluntly explains how he already is in possession of a drug that he plans to use:

(\#14) Hi, I've got hold on some Thai pills for a cycle that I'm going to run at some time. I plan to do $20-30 \mathrm{mg}$ per day. Is this dose too high and is there great risk of getting bitch tits from that amount? And if, can Nolvadex then prevent it if you take it as soon as you feel the symptoms? I know you don't advice on this, but I expect a good answer since I strongly consider starting the cycle. Thank you.

Yet another inquirer claims to be writing on behalf of his friend:

(\#15) Hi Expert, Here's a quick question: does it matter where you inject? I've got a friend that only does it in his biceps, but is that the correct way of doing it? He says it isn't important 'coz it automatically diffuses to the whole body?

As a state financed anti-doping agency ADD cannot advise on ('safe') ways to administer banned substances. Nonetheless, a potential dilemma arises for the consultant in such cases. To take \#15 as an example: to inject only into the biceps is not recommendable, and further, when administering repeated muscle depot injections, the injection site should be rotated to minimise the risk of infections and cysts (Beyea \& Nicoll, 1995; Evans, 1997; Rich, Dickinson, Flanigan, \& Valone, 1999).

As noted, part of the legal foundation that ADD as an institution rests is to "secure the health of the athletes", but in the case of, e.g. \#15 it becomes clear that the consultant is unable to disperse specific knowledge that at least in the short term could protect the inquirer and decrease associated health risks. With respect to \#13 and \#14 the problem is that although there are likely 'better' and 'worse' ways of administering anabolic steroids (Beyea \& Nicoll, 1995; Rich et al., 1999) such information cannot be given. The only

\footnotetext{
${ }^{8}$ Deca or Deca-Durabolin is the brand name for the anabolic steroid Nandrolone. Nandrolone (19-nortestosterone) is an anabolic steroid that may be present naturally in the human body, albeit in minute quantities. Nandrolone has structural modifications which reduce the likelihood of its conversion to oestrogen by aromatase enzymes, which means it has less adrogenic activity than many other anabolic steroids. Source: http://en.wikipedia.org/wiki/Nandrolone [visited: 9 May 2011].
} 
possible advice under the given policy would be to not use drugs at all. Given the determination to use steroids that is seen in some of these individuals, a likely result is that the inquirer rejects the advice and proceeds with steroid use based on the 'ethnopharmacological knowledge' he has acquired elsewhere (Monaghan, 2001).

The question thus arises whether the currently applied guidance policy is the optimal way to secure individuals' health in all situations. An alternative framework for anti-doping consultants would be to integrate knowledge from harm reduction programmes that has accumulated from this and other fields of drug use over the past 20 years. Harm reduction in this sense

encompasses interventions, programmes and policies that seek to reduce the health, social and economic harms of drug use to individuals, communities and societies. A core principle of harm reduction is the development of pragmatic responses to dealing with drug use through a hierarchy of intervention goals that place primary emphasis on reducing the health-related harms of continued drug use (Rhodes \& Hedrich, 2010).

Instead of applying a somewhat detached zero tolerance policy unanimously in all communication with drug users, harm reduction suggests a more pragmatic approach focusing on preserving the individual's health in his or hers specific situation, by e.g. aiming at lowering doses and increasing time off drugs (Evans-Brown \& McVeigh, 2009). Harm reduction programmes concerned with anabolic steroid use operates in both Holland and England. Here health personnel in clinics perform health checks of steroid users through, e.g. urine tests, blood tests, etc. and provide consultancy in order to guide individuals towards a healthier lifestyle. The outpatient clinic in Holland cooperates with the Dutch anti-doping authorities, while harm reduction clinics in England are disconnected from the sporting system (Dawson, 2001; de Ronde, 2012; Evans-Brown \& McVeigh, 2009).

Besides the fact that this is a sensitive area where politicians are reluctant to implement what could be considered a controversial policy, there are two possible explanation for why such an approach is not part of ADD's consultancy programme: (1) the institution would be sending out confusing signals as regards its stance on the doping issue, and 2) a change in the guiding principles is judged to lead to additional ethical dilemmas. If for instance $\# 15$, as a result of the consultant's advice under a different set of guidelines, adopts correct injection techniques he may experience fewer side effects and hence be less prone to cease his anabolic steroid use.

Taken together, it becomes clear that counselling on banned substances in the fitness environment is a delicate matter where unambiguous guiding principles are difficult to apply.

\subsection{Concerns for positive doping test}

Less problematic are inquiries from gym members who use dietary supplements. It is noteworthy that users of illegal substances like anabolic steroids rarely inquire about the risk of getting caught or obtaining a positive doping test in a gym (Bojsen-Møller \& Christiansen, 2010). This may be because they know the drugs they consider taking are illegal both in society at large and banned in sport, and therefore they regard it to be futile to inquire about. Some users of various dietary supplements on the other hand, seem unsure about the legal status of the substances they consume. Many of these inquiries are characterised by a concern that the inquirer may also be affected by the rules and regulations set up to fight the use of doping, although they do not consider themselves to be part of the target group of the legislation. Some simply ask whether the specific substance they have bought is safe to consume: (\#16) Is 'Animal Pak' legal in Denmark? Or does it contain drugs from the doping list? While others have more concrete worries about obtaining a positive doping test:

(\#17) I was in the gym working out yesterday. Then came a control officer and told me to be tested. I did it of course. But thought afterwards whether the supplements I've taken are banned. I take some creatine, and then I have eaten some 'Therma Power' but stopped using them more than 24 hours before the test. I don't suppose it will cause problems but would like to be $100 \%$ sure because I don't want to be thrown out of my gym because of that.

The concern is understandable. Because the Danish legislation on the issue is bound to the WADC the sanctions for a positive test are also in line with the WADC. A positive test - or a refusal to be tested - thus not only results in exclusion from the gym in which the test was taken and from all other gyms that are part of the scheme, but (ideally) from all organised sport in Denmark for a two-year period (Christiansen, 2011). Although a majority of gym members know whether there is doping control in their gym or not (Steele et al., 2010), they are not all aware about the details or what constitutes a doping infringement:

(\#18) Hello! If one takes 1 'Therma Power' [tablet] in relation to a desired weight loss, will this then show-up in a doping control in a gym? I mean do you test for this product? I took it 2 hours before my workout. Yes, it might be stupid, but if I've already taken it, it's good to know whether to be nervous for several weeks. The product contains $300 \mathrm{mg}$ of Ephedra $8 \%$ and $200 \mathrm{mg}$ of caffeine. Thanks in advance!

In this instance the inquirer's concern arises from the fact that 'Therma Power' is a slimming product that in some cases contains the stimulant ephedrine. According to the Danish Act on promotion of a doping-free sport it is WADA's list of banned substances that constitute the framework for what an individual can test positive for in a Danish gym (Retsinformation, 2004). Ephedrine/Ephedra is indeed on WADA's list of banned substances, but being a stimulant the WADC state that it is only to be tested for in competitions. Working out in a gym is not defined as an in-competition activity and thus stimulants are not tested for. However, from the data material it is evident that most inquirers are not aware of these subtle nuances.

Another consequence of having legislation bound to the WADC is that the principle of strict liability applies, which means that the individual is solely responsible for the substances found in his or her urine sample following a doping test.

(\#19) For a period I've eaten 'V12 Turbo', but the day before yesterday I was told that V12 is on the doping list. But is it really? And if I've already eaten it, but never knew it was banned, what do I do? Because if you test me, it will show I'm positive, even though I had no idea it was banned!

Irrespective of which banned drug the inquirer suspects could be present in ' $V 12$ Turbo', the problem raised is of some significance. In one study 634 dietary substances bought in 13 different countries mostly from shops but including 52 samples from the Internet, were analysed for their content. The analysis revealed that $15 \%$ of the products contained anabolic steroids that had not been declared on the labels of the products (Geyer et al., 2004). And even if there has been some improvement in the supplement business in recent years, the US Food and Drug Administration warned in December 2009 about a number of dietary supplements that potentially contained anabolic steroids (FDA, 2010). A warning that was also circulated in Denmark (The Danish Medicines Agency, 2010). Gym members' frequent usage of such substances is not without risk due to WADA's strict liability rule. To give an example: a gymmember buys and consumes a protein powder from the Internet. 
He discards the container and is few weeks later selected for a doping control in his gym and tests positive for nandrolone (which is one of the anabolic steroids frequently found in adulterated supplements). Although he claims his innocence and says the supplement he consumed must have been adulterated he is still likely to get a two-year ban due to the strict liability rule. The two-year ban, however, does not only apply to the gym in which the test was taken, but to all gyms that are part of the scheme, and (ideally) to all organised sport in Denmark. He is thus not only restricted from doing strength training in his gym but also from taking up badminton or bowling. Hence, concerns over contamination and unintended positive tests expressed by many inquirers are not unfounded.

\section{Conclusion}

This study examined two categories of inquiries to ADD's webbased counselling service: those inquiring about side effects from anabolic steroid use, and those inquiring about concerns for obtaining a positive doping test. The analysis demonstrated how inquiries covered a broad spectrum of motives and concerns, as well as differences in the way inquirers approached the web-service. Those inquiring about side effects of anabolic steroids could be grouped according to their approach to the service: one group consisted of individuals demonstrating lack of knowledge as regards effects and side effects of the hormones they expressed willingness to consume, another group consisted of traditional hotline-users who had experienced side effects from anabolic steroids, while a third group consisted of individuals who with so-called 'ethnopharmacological knowledge' claimed that risks and side effects of drugs could be handled in a calculative manner. Together with others, some in this latter group pose a separate challenge to ADD's consultants in that they inquired for health guidance while using anabolic steroids. ADD upholds a zero tolerance policy to drug use and have not applied harm reduction policies that might be beneficial for some individuals in this group. The analysis finally demonstrated how the Danish scheme for fighting use of anabolic steroids in gyms has also had an impact on individuals who demonstrated no apparent intention of violating the anti-doping rules, but who nevertheless are concerned for receiving a positive doping test and by so potentially losing access to organised sport.

\section{Perspectives}

Organisations aiming at eradicating or diminishing the use of anabolic steroids among strength training individuals in the general population are faced with a double challenge: on the one hand they are expected to take a zero tolerance approach, on the other, they must seek to minimise health problems among users and potential users. While the two aims in most cases cause no dilemmas, there are situations where conflicts arise. This is especially the case with individuals who cannot be persuaded to cease their drug use and perhaps possess an apparent substantial knowledge of drugs, hormones and cycles. Such 'ethnopharmacological' knowledge should not be idealised. The well circulated 'cycling theory', with its focus on periodic drug use, sometimes with the addition of recovery-drugs (e.g. quote \#11,12,14), is aimed at safeguarding the individual from self-damage. However, diminished side effects may prompt additional or continual drug use, which in turn may augment the risk of more serious self-damage due to e.g. irreversible effects on the cardiovascular system after years of anabolic steroid use (Hartgens \& Kuipers, 2004; Kanayama \& Pope, 2012; Parssinen \& Seppala, 2002). This however, does not mean that other approaches to safeguard individuals' health should not be considered. Harm reduction is one such approach. That such a policy has not been implemented in Denmark is probably related to the confusion that could arise from having a government sponsored anti-doping organisation apparently condoning the use of drugs. This issue has also been debated in England. Those against harm reduction schemes are arguing that consultants could be considered complicit in recreational athletes' drug use, while the counter argument is that if it is known that people are going to engage in risky and dangerous behaviours that are preventable at comparatively little cost in resources, then there is a strong ethical case that society ought to act to steer them away from these risks (DrugScope, 2004). This suggests that if harm reduction schemes for anabolic steroid users in gyms are to be accepted in the public sphere, and those who run the schemes are to avoid accusations of hypocrisy, it is necessary that control of doping among elite athletes is institutionally separated from the units acting out the harm reduction policy on recreational athletes in gyms. Thus, harm reduction policies do not imply the dismantling of conventional drug controls or education.

In line with the zero tolerance approach, educational campaigns aimed at avoiding anabolic steroid use have often applied a discourse focused on classic health related ideals such as vigilance, good health and moderation (Goldberg \& Elliot, 2000; Møller, 2009; Nilsson, Allebeck, Marklund, Baigi, \& Fridlund, 2004). There is, however, much empirical evidence that these standards are not compatible with the sub-cultural values possessed by many strength-training individuals using anabolic steroids (Barland \& Tangen, 2009; Grogan et al., 2006; Klein, 1993; Monaghan, 2001), and consequently the message has not the intended impact on the target group. This does not mean that these individuals adequately can be characterised as belonging to an anarchistic drug sub-culture where health is simply abandoned, which is evident from the number of individuals addressing health concerns in connection with anabolic steroid usage (e.g. Bojsen-Møller \& Christiansen, 2010; Monaghan, 2001). Rather, it points to differences in the cultural premises, where one side accepts the validity of potential harm minimisation through competent risk assessment and risk management while the other rejects it. Thus, future research should seek strategies for communication and education that can bridge these perceived differences in knowledge and human interests.

\section{Conflicts of interest}

None.

\section{Acknowledgments}

The authors would like to thank Anti Doping Denmark for their collaboration on this project and for giving us access to their database. There was no financial assistance with the project.

\section{References}

Anti Doping Danmark. (2012). Anti Doping Danmark. http://www.antidoping.dk/ Anti Doping Danmark. (2012b). Steroids.dk. http://www.antidoping.dk/sitecore/ content/steroids_dk/FrontPage.aspx

Anti Doping Danmark. (2012). Strategy for stopping steroids. Copenhagen: Anti Doping Danmark.

Barland, B., \& Tangen, J. O. (2009). Kroppspresentasjon og andre prestasjoner - en omfangsundersøkelse om bruk av Doping (Rep. No. 2009:3). Oslo: Politihøgskolen.

Beyea, S. C., \& Nicoll, L. H. (1995). Administration of medications via the intramuscular route: An integrative review of the literature and research-based protocol for the procedure. Applied Nursing Research, 8, 23-33.

Bhasin, S., Storer, T. W., Berman, N., Callegari, C., Clevenger, B., Phillips, J., et al. (1996) The effects of supraphysiologic doses of testosterone on muscle size and strength in normal men. The New England Journal of Medicine, 335, 1-7.

Bilard, J., Ninot, G., \& Hauw, D. (2011). Motives for illicit use of doping substances among athletes calling a national antidoping phone-help service: An exploratory study. Substance Use E' Misuse, 46, 359-367.

Bojsen-Møller, J., \& Christiansen, A. V. (2010). Use of performance- and image enhancing substances among recreational athletes: A quantitative analysis of 
inquiries submitted to the Danish anti-doping authorities. Scandinavian Journal of Medicine E'Science in Sports, 20, 861-867.

Christiansen, A. V. (2009). Doping in fitness and strength training environments-politics, motives and masculinity. In V. Møller, M. McNamee, \& P. Dimeo (Eds.), Elite sport, doping and public health (pp. 99-118). Odense: University Press of Southern Denmark.

Christiansen, A. V. (2011). Bodily Violations: Testing citizens training recreationally in gyms. In M. McNamee, \& V. Møller (Eds.), Doping and Anti-doping. Ethical, legal and social perspectives (3rd ed., pp. 126-141). London: Routledge.

Dawson, R. T. (2001). Drugs in sport-the role of the physician. Journal of Endocrinology, 170, 55-61.

de Ronde, W. (2012). Health risks associated with abuse of androgenic anabolic steroids. In Sportvision.

DrugScope. (2004). The doping scandal: A question for sport? DrugScope,. www.drugscope.org.uk

Eklöf, A. C., Thurelius, A. M., Garle, M., Rane, A., \& Sjöqvist, F. (2003). The anti-doping hot-line, a means to capture the abuse of doping agents in the Swedish society and a new service function in clinical pharmacology. European Journal of Clinical Pharmacology, 59, 571-577.

European Commission. (2007). White Paper on Sport. Brussels: European Commission.

Evald, J. (2009). Retlige grænser for dopingkontrol (Legal boundaries for doping control). In A. V. Christiansen (Ed.), Kontrolsport-Big brother blandt atleter og tilskuere (pp. 71-88). Odense: Syddansk Universitetsforlag.

Evans, N. A. (1997). Local complications of self administered anabolic steroid injections. British Journal of Sports Medicine, 31, 349-350.

Evans-Brown, M., \& McVeigh, J. (2009). Anabolic steroid use in the general population of the United Kingdom. In V. Møller, M. McNamee, \& P. Dimeo (Eds.), Elite sport, doping and public health (pp. 75-97). Odense: University Press of Southern Denmark.

FDA. (14-12-2010). Press Release-BODYBUILDING.COM Is Conducting a Voluntary Nationwide and International Recall of 65 Dietary Supplements That May Contain Steroids. http://www.fda.gov/Safety/Recalls/ucm188929.htm. US Food and Drug Administration, 9-6-2011.

Geyer, H., Parr, M. K., Mareck, U., Reinhart, U., Schrader, Y., \& Schanzer, W. (2004). Analysis of non-hormonal nutritional supplements for anabolic-androgenic steroids-results of an international study. International Journal of Sports Medicine, 25, 124-129.

Goldberg, L., \& Elliot, D. L. (2000). Prevention of anabolic steroid use. In C. E. Yesalis (Ed.), Anabolic Steroids in Sport and Exercise (2nd ed., pp. 117-135). Champaign, IL: Human Kinetics.

Graham, M. R., Ryan, P., Baker, J. S., Davies, B., Thomas, N. E., Cooper, S. M., et al. (2009). Counterfeiting in performance- and image-enhancing drugs. Drug Testing and Analysis, 1, 135-142.

Grogan, S., Shepherd, S., Evans, R., Wright, S., \& Hunter, G. (2006). Experiences of anabolic steroid use: In-depth interviews with men and women body builders. Journal of Health Psychology, 11, 845-856.

Hartgens, F., \& Kuipers, H. (2004). Effects of androgenic-anabolic steroids in athletes. Sports Medicine, 34, 513-554.

Kanayama, G., \& Pope, H. G., Jr. (2012). Illicit use of androgens and other hormones: Recent advances. Current Opinion in Endocrinology, Diabetes and Obesity, 19, 211-219.

Klein, A. M. (1993). Little big men: Bodybuilding subculture and gender construction. Albany: State University of New York Press.

Mangweth, B., Pope, H. G., Jr., Kemmler, G., Ebenbichler, C., Hausmann, A., De, C. C., et al. (2001). Body image and psychopathology in male bodybuilders. Psychotherapy and Psychosomatics, 70, 38-43.

Møller, V. (2009). Conceptual confusion and the anti-doping campaign in Denmark. In V. Møller, M. McNamee, \& P. Dimeo (Eds.), Elite sport, doping and public health (pp. 13-28). Odense: University Press of Southern Denmark.
Møller, V. (2010). The ethics of doping and anti-doping: Redeeming the soul of sport? London: Routledge.

Monaghan, L. F. (2002). Vocabularies of motive for illicit steroid use among bodybuilders. Social Science \& Medicine, 55, 695-708.

Monaghan, L. F. (2001). Bodybuilding, drugs, and risk. London: Routledge.

Mottram, D. R. (2011). Drugs in sport (5th ed.). London: Routhledge.

Nilsson, S., Allebeck, P., Marklund, B., Baigi, A., \& Fridlund, B. (2004). Evaluation of a health promotion programme to prevent the misuse of androgenic anabolic steroids among Swedish adolescents. Health Promotion International, 19, 61-67.

Parkinson, A. B., \& Evans, N. A. (2006). Anabolic androgenic steroids: A survey of 500 users. Medicine E' Science in Sports E Exercise, 38, 644-651.

Parssinen, M., \& Seppala, T. (2002). Steroid use and long-term health risks in former athletes. Sports Medicine, 32, 83-94.

Perry, P. J., Lund, B. C., Deninger, M. J., Kutscher, E. C., \& Schneider, J. (2005). Anabolic steroid use in weightlifters and bodybuilders: An internet survey of drug utilization. Clinical Journal of Sport Medicine, 15, 326-330.

Pope, H. G., Kanayama, G., Ionescu-Pioggia, M., \& Hudson, J. I. (2004). Anabolic steroid users' attitudes towards physicians. Addiction, 99, 1189-1194.

Pope, H. G., Phillips, K. A., \& Olivardia, R. (2000). The Adonis complex. How to identify, Treat, and Prevent Body Obsession in Men and Boys. New York: Free Press.

Probert, A., Palmer, D. F., \& Leberman, D. S. (2007). The Fine Line: An insight into 'risky' practices of male and female competitive bodybuilders. Annals of Leisure Research, 10, 272-290.

Retsinformation. (27-12-2004). Lov om fremme af dopingfri idræt (Act on Promotion of Doping-free Sport), 1438.

Retsinformation. (29-5-2008). Lov om ændring af lov om fremme af dopingfri idræt (Act on change of Act on Promotion of Doping-free Sport). Ref Type: Bill/Resolution.

Rhodes, T., \& Hedrich, D. (2010). Harm reduction and the mainstream. In T. Rhodes, \& D. Hedrich (Eds.), Harm reduction: Evidence, impacts and challenges (pp. 19-33). Luxembourg: European Monitoring Centre for Drugs and Drug Addiction.

Rich, J. D., Dickinson, B. P., Flanigan, T. P., \& Valone, S. E. (1999). Abscess related to anabolic-androgenic steroid injection. Medicine E' Science in Sports E' Exercise, 31, 207-209.

Sjöqvist, F., Garle, M., \& Rane, A. (2008). Use of doping agents, particularly anabolic steroids, in sports and society. Lancet, 371, 1872-1882.

Skårberg, K., Nyberg, F., \& Engstrom, I. (2008). The development of multiple drug use among anabolic-androgenic steroid users: Six subjective case reports. Substance Abuse Treatment, Prevention, and Policy Journal, 3, 24.

Spitzer, G. (1998). Doping in der DDR: Ein historischer Überblick zu einer konspirativen Praxis: Genese - Verantwortung - Gefahren. Köln: Sport und Buch Strauss.

Steele, R., Bang, S., Brandt, H. H., \& Kirkegaard, K. L. (2010). (the fight against doping in commercial fitness centres - an evaluation of the labelling scheme) Indsatsen mod motionsdoping $i$ kommercielle motions- og fitnesscentre - en evaluering af mærkningsordningen. København: IDAN, Idrættens Analyseinstitut (Danish Institute of Sport Studies).

Striegel, H., Simon, P., Frisch, S., Roecker, K., Dietz, K., Dickhuth, H. H., et al. (2006). Anabolic ergogenic substance users in fitness-sports: A distinct group supported by the health care system. Drug and Alcohol Dependence, 81, 11-19.

The Danish Medicines Agency. (27-1-2010). Advarsel mod piller fra IDS Sports. http://laegemiddelstyrelsen.dk/en/service-menu/product-information/newson-product-information/warning-against-pills-from-ids-sports-. Lægemiddelstyrelsen, The Danish Medicines Agency (accessed on 10.6.11).

Thompson, J. K., \& Cafri, G. (2007). The muscular ideal: Psychological, social, and medical perspectives. Washington, DC: American Psychological Association.

Todd, T. (1987). Anabolic steroids: The gremlins of sport. Journal of Sport History, 14, 87-107.

Waddington, I., \& Smith, A. (2009). An introduction to drugs in sport: Addicted to winning? (2nd ed.). Abingdon: Routledge. 